\title{
A review of adults with disabilities transitioning from their family home to community settings
}

\author{
Garry Lim University of Waikato Aotearoa New Zealand
}

\begin{abstract}
INTRODUCTION: This study examined the experiences of adults with disabilities (AWDs) transitioning to community based residential settings. This field of study has not been sufficiently researched despite being a key aspect of adulthood.

METHOD: A literature review of articles relating to residential transitions for AWDs was undertaken.

FINDINGS: The literature review findings could be grouped around three main categories: AWDs' perception and self-determination, caregivers' perceptions of the process and, lastly, the insights from service providers and social policies. The review and feedback identified issues experienced during the residential transition, such as feelings of readiness to transit which relate closely to the person's self-determination. As the study delved deeper into the residential transition process in Aotearoa New Zealand, AWDs are noted to be vulnerable persons always requiring support in order to develop and maintain their independence.
\end{abstract}

IMPLICATIONS: Substantive state recognition, such as a social compact, is the key groundwork for this marginalised group to develop self-efficacy, have successful transition experiences and sustain good lives. Eventually, this must be in the form of Crown-binding legislation, where vulnerable adults are served through restorative and protective policies.

KEYWORDS: disability, adult disability, independent living

Adults with disabilities living independently in the community is not a new phenomenon in most first-world Western countries (Grey, Griffith, Totsika, \& Hastings, 2015; Henninger \& Taylor, 2014; Stewart, Gates, Milner, MirfinVeitch, \& Schumayer, 2008). In Western economies such as the USA, Australia and the UK, between $6 \%$ and $16 \%$ of adult, working-age people identify as having a disability (Winn \& Hay, 2009). The identified statistics give the independent living movement a voice and, more crucially, a level of political consciousness. However, as with most social services and movements, the systems and programmes supporting independent living have largely happened in lieu of a distant disability voice.

The purpose of this study was to identify crucial elements cited within contemporary studies regarding transition to community settings and highlight systemic changes in the group. Limiting the study to residential transitions serves to guide readers to appreciate the unique facets that surface and their impact on outcomes for both AWDs and their caregivers.

The objectives of the study were to:

1. explore how AWDs and caregivers conceive the transition experience to community based living; 
2. identify key factors found in a literature search which influence the transition from home for AWDs.

3. investigate the services that support transitioning to independent living. These are primarily taken from research sources but also from comments made through written feedback sought various New Zealand disability agencies;

4. provide recommendations from the results of the earlier objectives relevant to the future direction of disability transition research.

This report features a key facet of transitions for AWDs transitioning from home to independent living. This aspect of transition was chosen due to its significance to perceived successful adulthood for two main reasons:

1. Living in one's own home is a key determinant of reaching adulthood (Grey et al., 2015; Jokinen, Janicki, Hogan, \& Force, 2012). Henninger and Taylor (2014) determined, through their study, that the two most successful outcome categories for reaching adulthood were moving from one's home and having a functional role in society.

2. As AWDs age, naturally their caregivers will age in tandem. The growing physical and emotional limitations are strains on the family systems. Moving out of their families' home not only allows families to pursue their own life goals, it gives caregivers a much-desired freedom to spend more time outside of their care roles (Grey et al., 2015). Thus, it can be seen that there are benefits for both parties within this transition.

An added dimension to this study will include feedback from New Zealand disability service sector organisations to identity local good practices that can enhance more inclusive and independent living for AWDs.

\section{Definitions}

\section{Disability}

The terms adults with disability, young adults with disability and disabled adults were generally used synonymously in the articles analysed. While these terms imply similar meanings, the various labels point to a significant element of this review. In contrast to labelling disability as a medical or health problem, there is an absence of a clear description that views disability as a complex, interactive experience with an emphasis on socially created barriers. Due to this, the World Health Organisation definition of disability is used, as below:

Disabilities is an umbrella term, covering impairments, activity limitations, and participation restrictions. An impairment is a problem in body function or structure; an activity limitation is a difficulty encountered by an individual in executing a task or action; while a participation restriction is a problem experienced by an individual in involvement in life situations. (World Health Organisation, 2015)

In order to capture a wide range of disabilities' content, this study searched for words describing adults with all types of disabilities.

\section{Transition}

Schlossberg (1995) determined that a transition is a transition only if it is so defined by the person experiencing it. On the other hand, many might argue that life is basically a series of transitions; the key point is that change occurs in someone's life, not that it was a choice (Clegg, Murphy, \& Almack, 2010). The ability and wish to make choices independently is recognised as a milestone on the pathway of transitioning into adulthood. This can be inferred by readers from a normative social standpoint and, more importantly, from a legislative stance. Within Aotearoa New Zealand, there is no legislation 
that allows for the state to withhold or rescind the rights of AWDs. There are statutory frameworks in place to provide a community voice but the state is not given powers to act otherwise (New Zealand Parliamentary Counsel Office, 2000). This argument is made in contrast to the Children, Young Persons, and Their Families Act (1989) and the Vulnerable Children Act (2004) which provide authority to act for children, not adults. This encapsulates the idea, and essence, of self-determining choice and independence as an outcome of reaching adulthood. Due consideration is given to adults with severely diminished communicative capabilities in that they require co-proxies to convey their points of view.

\section{Key disability theories}

The following theoretical perspectives related to disability and transitions are presented as they inform the orientation of this study. A brief explanation of relevant theories is provided.

\section{Medical model of disability}

From the perspective of the medical model disability is primarily the result of a physical condition specific to the individual (Brisenden, 1986). Doctors play a key role in their lives by stabilising a person's condition and treatment of any illnesses that may, or may not, arise from the disability. The mass institutionalisation of people with disabilities in medical facilities was widely accepted during an era when this model of thought was at its strongest (Berry, 1995; Weinbach, 2009).

This has led to some opponents of a medical view of disability to "correct the wrong" in this argument. Michael Oliver suggested that the ideology of attaining normality via correction may not always be a simple medical procedure (Oliver, 1990). He determined that society has to change in order to include people of all functioning abilities, thus achieving a good, normal life through normalisation.
Likewise, Shakespeare determined that an illness view of disability is unquestionably flawed; a prioritisation of social change and barrier removal is mooted. However, viewing disability as only a social condition does not acknowledge that people may be disabled by social barriers and anatomy (Shakespeare, 1999; Vehmas \& Shakespeare, 2014). Appropriate action on disability and impairment prevention should co-exist with actions to remove social barriers and practices (Shakespeare, 2013).

\section{Normalisation}

As an alternative to mass institutionalisation, the normalisation perspective (Nirje, 1969; Wolfensberger, 1977) sought to ensure that "the mentally retarded obtain an existence as close to the normal as possible" (Bank-Mikkelsen, 1969). This school of thought argued that the conditions of daily living for people with disability must be similar to those of wider society (Nirje,1985). Nirje's original ideas were taken up by Wolfensberger (1977) who introduced this principle to the United States, refashioned as social role valorisation (SRV). Wolfensberger (1983) outlines that the main objective of normalisation is to support, create, and defend the valued social roles for persons who are at risk of being socially devalued. This model is applied extensively to people with a primary diagnosis of intellectual disability. Through the physical and social integration of people with intellectual disabilities, it was hoped that they experience the same life value and conditions as other people. The road to self-determination and decision making is often more challenging and all the more important for a person with intellectual disability (Nirje, 1985). In general, people with intellectual disabilities experience greater stigma in comparison to people with other disabilities (Werner, 2015). They often face more negative stereotypes and social distance within the disability types. 
This perspective may overtly devalue the identity of the person based on the need to seek a higher social standing (Davis, 2014). Later studies have found that, while these ideas have improved living conditions, they have had little impact on other desired outcomes such as the development of sustained social relationships over time (Forrester-Jones et al., 2006). In one study, Emerson (2005) identified that almost $20 \%$ of participants reported no social contact with family or friends in the previous year. Startlingly, one in three people surveyed shared that someone had been rude to them due to their learning disability. Likewise, modifying or enhancing people to look more normal may not always be in line with the persons' individuality. Consequently, people not only experience a lack of caring arrangements but they also lacked places where they can feel emotionally connected (Marston \& McDonald, 2006). Unfortunately, the integrative approach, valued by normalisation theorists, can lead to unsustainable assumptions about what normality means for people with disability.

\section{Social model of disability}

This model views disability as a social construct that is based on the assumption that society disables people by the way it responds to those disabilities (Oliver, 2013). The barriers constructed by society include social discrimination, inaccessible environments and the general way society has organised itself to suit abled persons. The social model advocates for an inclusive, barrier-free society. Problems created within the social context have to be addressed to find ways to remove restrictions on life choices for people with disability. This principle of thought is especially popular among self-advocates and activists.

Shakespeare (1999) has challenged the denial of impairment implied by this model, concerned about the impact of the physical and intellectual inherent limitations on possibilities for working within a social model understanding of disabling conditions. Owens (2015) similarly stated that the social model of disability lacks engagement with the embodied experience of disability and with the identities of disabled people. From contemporary texts, there is no clear answer to this embodied versus social conundrum. Of late, the social model of disability has been heavily critiqued with calls to move beyond it (Owens, 2015; Shakespeare \& Watson, 2001) and towards a set of principles that sufficiently encapsulate the inclusiveness of a social model, and at the same time, address the real physical needs of disabled people.

\section{Dismodernism}

Dismodernism is the term Davis (2014) used to describe another paradigmatic shift. There are arguments that propose an embodied ontology when there is no qualitative divide between persons with, or without, disability (Davis, 2014). Davis evaluates that disability is often sharply defined as a life not worth living and hence, a personal tragedy. On the other hand, the term diversity provides a concept of subjectivity where people are placed on a continuum that is socially constructed. Diversity seeks to remove the notion of "normality" where there is an unhealthy preoccupation with deviant finding, labelling and stigmatisation. These principles challenge the entrenched idea of creating a disability sector where the sector should acknowledge that dependency is the reality for everyone; the only guarantee about a body is that it is inherently limited in some way or another. The social categorisation that currently exists may allow resources to be channelled towards a "disabled" group, however, it also stigmatises people who are part of this group as being on the fringe of normal society. Dismodernism incorporates the value that impairment is the rule, normality is a fantasy.

\section{Transition theory}

A study on transitioning to community living is a multi-directional relationship process that requires application of transition models and theories to provide a readable structure. This study uses 
the bioecological model and proximal processes (Bronfenbrenner \& Morris, 2007) to structure the review and illustrate the identity development of the individuals involved. It is an extension of the ecological systems theory (Bronfenbrenner, 1992) which establishes five environmental systems with which a person interacts. Bronfenbrenner and Morris' (2007) bioecological model is one that prioritises person-to-environment interactions in human development.

Usage of this model will support the reader's understanding of two-way relationships and influences acting on the development of AWDs and the changes happening in their surrounding systems. As a framework to structure the study, it will enable the study to identify the relationship dynamics impacting on the person and his or her community.

The theoretical positions summarised above will be linked to the concept of AWDs' transition into adulthood-specifically community-based living.

\section{Literature Review}

\section{Methodology}

The overarching research question underpinning my literature review is: What common factors affect adults with disabilities' successful transition to more independent living settings? Ethical approval was given by the University of Waikato's Faculty of Education Research Ethics Committee to send a series of questions to five disability-related agencies about how they view disability residential transitions. A full summary of the methods and further information gained is available upon written request.

\section{Results}

Three key elements affecting the outcomes of residential transitions were identified in the critical exploration of the literature: selfdetermination; next of kin expectations and involvement; and lastly, social policies.

\section{AWDs' perceptions and self-determination}

The articles found during the review process explored this concept through the theme of focussing on the individual's own voice and perceptions during independent living transitions. Three studies used a qualitative methodology and employed semi-structured interviews as the main medium to explore the experiential views, thoughts, and feelings of AWDs as they made the transition from home to independent living. The methodological essence of these studies was comparatively narrow and the disability diagnosis types investigated were well defined. Critically, three studies related only to AWDs, and were typically based on samples from Western countries. The results of these studies point towards the idea that the transition process is a challenging and emotionally stressful time. A detailed analysis of the key findings of studies is included below.

Summary. The reviewed articles demonstrated that participants, AWDs, are able to display self-determining life aspirations for independent living. The AWD in the centre of different systemic relationships and interactions is an important aspect of understanding human development. However, the caregiver relationship is either a pervasive or ubiquitous influence on the AWD in providing support to those who wish to live independently (Bronfenbrenner \& Morris, 2007). Furthermore, a lack of social interactions with normal, contemporary society is probably the unintentional barrier that limits AWDs' opportunity to exercise rights to make life determinations. In addition, most of the respondents were proxies such as parents and staff-the voice of the AWD is essentially absent.

Self-determination is a conceptual extension of the principle of normalisation (Nirje, 1985). It grew from the idea of encouraging people with learning disabilities to speak up for themselves, make their own lifestyle choices and to enact them (Drew \& Hardman, 2000). 
Therefore, an adult's voice in deciding the kind of independent living choices is an indispensable detail during the transition pathway. There is a narrow line families and staff have to tread between protecting the adults and affirming their rights. It may take a great deal of inner strength for a caregiver to come to a realisation that, while not all choices made by a person with disability are the most optimally safe (physically or emotionally), they are still theirs to make.

The literature provides evidence of the variety of AWDs' experiences in making informed choices, and the function of others in supporting their wishes. Social workers and other professionals can perform an invaluable role in supporting AWDs and their families to connect with wider social systems. This will increase the AWDs' social capital, accessible information and enable formation of trusted relationships. The experiential cognitive standpoint of AWDs in deciding their living choices is an essential part of a transition journey. Palmer (2010) established that self-determination, as a construct, requires a discerning understanding of independence with a focus on making choices about life. This review found articles which promoted the belief that the voice of an AWD in deciding their type of living choices is an integral part of the transition journey. It also assures a holistic and positive outcome to successful residential transitions.

\section{Family perceptions of the transition process}

This theme focused on the family and caregivers' perception and experiences during the transition to independent living. Seven articles were mapped under this theme in respect of their high relevance and impact. Six of seven studies used qualitative methodology and employed semi-structured interviews as the main medium to explore the familial experiences during the transition from home to independent living. The methodological essence of all the studies was comparatively narrow and the disability type investigated was restricted. Critically, six studies focused solely on individuals with intellectual disability, and were typically based on samples of AWDs from Western countries. The results of these studies point towards the family as a key resource during the transition process. Appendix 1 provides a table synopsis of the seven articles.

Summary. It is interesting to note that families and caregivers play a strong role in all the studies in the review. All 15 studies highlighted direct caregiver involvement as a crucial part of residential transition. In the seven articles reviewed above, attention is drawn to the notion that the management of daily life living beyond the family home requires an individually tailored support package.

The family perspective is crucial for an implementable, individualised transition plan, as not all parents of AWDs share the same aspirations and concerns. Professional workers have to be equipped with attitudes, skills and knowledge pertaining to the specific disability, particularly if a lifelong caring and/or support role is required. This theme is closely related to the mesosystem (in the bioecological systems theory) which suggests that the AWD's family systems contain unique norms and rules which helps to shape the persons' psychological development. The family system is a key component of the AWD's environment. Namely, it is the first relationship the person would establish him or herself in and is the most basic unit of society. The early beginnings of developing secure attachments through these relationships is central to what the person will come to know as an extension to their perception of the wider community (Bronfenbrenner \& Morris, 2007). The conclusions above demonstrated that practitioners need to build a caregiver partnership through mutual trust, accessibility and clear communication. Through such practices, the success of transitioning towards community based independent living will likely increase. 
Key insights from disability services and social policies

Five studies described the insights from professional services and policy influences. Most of these articles were qualitative in nature and from Western countries. The power to effect change and provide support to the AWD within the environment often lies within various cultural, political and economic patterns, societal customs and nationality. Referencing Bronfenbrenner's bioecological systems model, government policies, cultural values, customs, and laws affecting AWDs are within the outer-most layer of the model, the macrosystem. The result of larger principles characterised by the macrosystem are often the causal agents that cascade influence throughout the interactions of all other systems within the concentric layers (Bronfenbrenner \& Morris, 2007).

Summary. This study reveals that stable residential transitions require the implementation of policies that acknowledge the rights of an AWD and the support of family and caregiver advocacy. At the same time, the studies revealed an inexplicable conundrum where rights are given but the policies and programmes do not seem sufficient. Are rights enough, then?

From the Ministry of Social Development's "New Zealand Disability Strategy" (MSD, 2015), Aotearoa New Zealand citizens with disabilities' rights are covered under numerous legislations. For instance, the Bill of Rights Act, the Privacy Act, and the Human Rights Act. The 1975 Disabled Persons Community Welfare Act (New Zealand Parliamentary Counsel Office, 1975) focused extensively on practical provisions for people with disabilities. It is important to note that this act has since seen many of its sections repealed, such as that providing assistance specific to families and persons with disabilities and assistance to disabilitybased voluntary organisations. Only some of the repealed sections were subsumed in the Health and Disability Services Act (New Zealand Parliamentary Counsel Office, 2001).
The legislation referred to above aims to acknowledge disability rights but generally lacks features enabling the participatory capacity of AWDs. AWDs usually rely on family resources as their only option when independent living support services have long waiting lists. From a person-centred practice, it would seem that a rights-based course needs a caveat that the person must have a determined aptitude to voice his or her rights and for such rights to be viewed as inalienable to the disability sector. This theme highlighted the significance of enhancing policy implementation to grant voice to the voiceless.

\section{Final Summary}

Overall, this review found that local services may reach a more ideal residential transition outcome if the needs and challenges were identified early and support plans were in place. Service staff need to be skilled at identifying any obstructions involved as they emerge and ameliorate them before they pose harm; likewise there is need for a professional set of values and attitudes. Working together and developing crucial partnerships to support AWDs would require all stakeholders to listen to and action their aspirations and needs and have a living document to consistently engage the people to contribute their voice.

Within Aotearoa New Zealand's context, a person under 18 has certain choices and rights withheld in accordance with state legislation. Legislatively, choice is not always an option for young people. The state assumes responsibility for improving the well-being of young persons in relation to the setting of government priorities under the Children, Young Persons, and Their Families Act and the Vulnerable Children Act (New Zealand Parliamentary Counsel Office, 1989, 2014). The principle of adequate care and well-being is questioned if non-age-related concerns that define vulnerable children continue to permeate and exist after the age of 18 -especially so for AWDs. 
Additionally, rights-based policies might not always involve the voice of the vulnerable disabled adult. Evidently, any discussion on social justice and rights-based systems is a disputable space that hovers between the two. Regardless, these identified support needs for both social justice and rights are focused on enabling an AWD to aspire to, pursue and live a good life. Both have shown limited efficacy without the other and action to shift preexisting mind-sets and interventions is often challenging.

Social justice requires potent, political, legislative action to provide insight and headway into the betterment of the lives of AWDs; a prescription of government priorities is conditional to such outcome. At the same time, the presence of unique vulnerable disabled adult legislation should be in place to guide the executive functions of the state in crafting suitable social policies. Such a Crown-binding act will need to support the government's setting of policies that improve the well-being of vulnerable disabled adults through disability related agencies working together. In Aotearoa New Zealand, AWDs could benefit from being accorded a set of adult disability statute orders that recognise their unique vulnerability, prevent discrimination and protect their well-being. For instance, it could contain provisions on reporting and identification of abuse and neglect specific to AWDs or even mandatory safety checks around work that involves regular or overnight contacts.

Finally, Davis' (2014) position on dismodernism may well provide a new future that helps agencies and caregivers to think differently about support requirements. Davis notes the paradigmatic influences that dictate everyday notions of normal assumptions and how these perpetuate a society that limits inclusiveness and asks readers if we are contemporary members of society complicit in perpetuating a mentality that limits AWDs. Davis points towards a distant future, that only when given time, activism and education, we will come to see people on a single continuum scale of functionality. Disability exists in all and diversity is the new human identity; a way of life, not simply a violation of a medical norm.

\section{Discussion and Conclusion}

Transitioning into adulthood can be a perilous experience for AWDs who require support throughout their lifespans. It can also be an exciting time with new social stimulus and opportunities for both the adult and the caregivers involved. In identifying key factors acting on the transition process between family home and independent living, Figure 1 summarises the main themes and the interacting tri-directional forces: the person, family and professional services.

The three overlapping circles represent transition factors and illustrate how the combination of all three would create an ideal scenario; optimised to increase the success rate for effective community transitions. The literature review suggests that these factors interact to influence general transition experiences and outcomes. This review submits that disability transitions are complicated, interactive phenomena marked by the presence of very real, socially created barriers.

One study (Janus, 2009) stood out in identifying four main adult transitions: establishing an independent residence; marrying; having children; and finding full-time employment. These four adulthood goals follow closely the milestones seen in adults without disabilities. Needless to say, AWDs failed to measure in most of these constructs. The capability to "measure up" to normal adulthood goals is also present in several other studies reviewed (Hendricks \& Wehman, 2009; Jokinen et al., 2012; Leiter \& Waugh, 2009; Pallisera, Vilà, \& Fullana, 2014). This sparked a question as to whether AWDs truly owned said adulthood transition outcomes if they mirror the "normal" status quo.

Perhaps Davis (2014) gives an insight into finding a different way to represent AWDs' adulthood. First, we seek to 


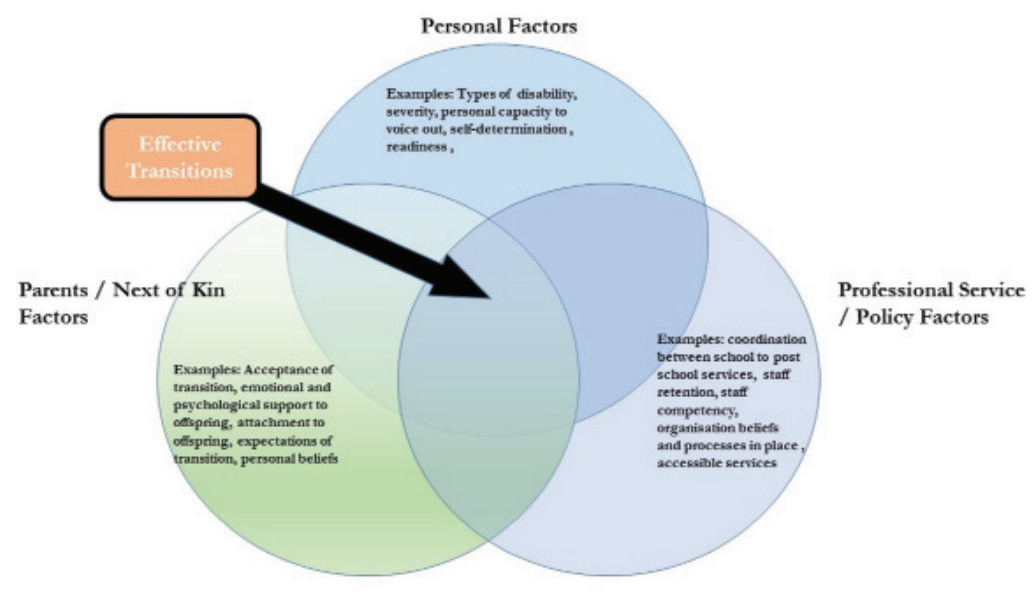

Figure 1: Effective transitions
Based on the findings of this review, and in fulfilling the last objective of the study, future research is recommended in the following areas:

1. How does an AWD experience and live the transition experience in respect to self-determination?

Studies could explore the adults' experience in their social reality, based on their beliefs, values and aspirations. The next step in residential transition success is likely through self-determination and the type of skills essential to enhancing critical interests. Further research into this area will add to the service users' perspectives and promote the development of initiatives that are tailored to the individual.

2. What would affect the level of selfdetermination during transitions to community living?

Such research would explore the relationships between the variables and also support professional services to identify adults at risk of unfavourable residential transition situations.

In conclusion, the review identified issues experienced during a person's residential transition. These include feelings of readiness to transit which relate closely to the person's self-determination. The passing of vulnerable disabled adult statute legislation and subsequent social policies in place to enhance the person's perception of self-efficacy can be seen as the key groundwork for a successful transition experience.

\section{References}

Bank-Mikkelsen, N. (1969). A metropolitan area in Denmark: Copenhagen. In R. Kugel \& W. Wolfensberger (Eds.), Changing residential patterns for the mentally retarded (pp. 363-376). Washington DC: President's Committee on Mental Retardation.

Berry, J. O. (1995). Families and deinstitutionalization: An application of Bronfenbrenner's social ecology model. Journal of Counseling and Development, 73(4), 379383. Retrieved from http://search.proquest.com.ezproxy. waikato.ac.nz/docview/229806036?pq-origsite=summon

Brisenden, S. (1986). Independent living and the medical model of disability. Disability, Handicap \& Society, 1(2), 173-178. doi.org/10.1080/02674648666780171 
Bronfenbrenner, U. (1992). Ecological systems theory. In Vasta, R. (Ed.) Six theories of child development: Revised formulations and current issues (pp. 187-249). London, England: Jessica Kingsley Publishers.

Bronfenbrenner, U., \& Morris, P. A. (2007). The bioecologica model of human development. In Damon, R \& Lerner, W.M. (Eds. ) Handbook of child psychology. John Wiley \& Sons, Inc. Retrieved from http://onlinelibrary.wiley.com/ doi/10.1002/9780470147658.chpsy0114/abstract

Clegg, J., Murphy, E., \& Almack, K. (2010). Transition: A moment of change. In Grant, G., Ramcharan, P. Flynn, M., \& M.Richardson, M. (Eds.) Learning disability: A life cycle approach (pp. 203-216). UK: McGraw-Hill Education (UK).

Davis, L. (2014). The end of normal: Identity in a Biocultural Era. Ann Arbor: University of Michigan Press.

Department of Justice. (2010). 2010 ADA regulations. Retrieved from http://www.ada.gov/2010_regs.htm

Drew, C. J., \& Hardman, M. L. (2000). Chapter 10: The adult with mental retardation. In Hardman, M.L. Ed., Mental retardation: A life cycle approach (7th ed., pp. 292-320). Upper Saddle River, NJ: Prentice Hall.

Emerson, E. (2005, September 28). Adults with learning difficulties in England 2003/04 [Publication]. Retrieved from http://webarchive.nationalarchives. gov.uk/20130107105354/http:/www.dh.gov. uk/en/Publicationsandstatistics/Publications/ PublicationsStatistics/DH_4120033

Forrester-Jones, R., Carpenter, J., Coolen-Schrijner, P., Cambridge, P., Tate, A., Beecham, J., ... Wooff, D. (2006) The social networks of people with intellectual disability living in the community 12 years after resettlement from long-stay hospitals. Journal of Applied Research in Intellectual Disabilities, 19(4), 285-295. http://doi. org/10.1111/j.1468-3148.2006.00263.x

Grey, J. M., Griffith, G. M., Totsika, V., \& Hastings, R. P. (2015). Families' experiences of seeking out-of-home accommodation for their adult child with an intellectual disability. Journal of Policy and Practice in Intellectual Disabilities, 12(1), 47-57. http://doi.org/10.1111/ jppi.12106

Hendricks, D. R., \& Wehman, P. (2009). Transition from school to adulthood for youth with autism spectrum disorders: Review and recommendations. Focus on Autism and Other Developmental Disabilities, 24(2), 77-88.

Henninger, N. A., \& Taylor, J. L. (2014). Family perspectives on a successful transition to adulthood for individuals with disabilities. Intellectual and Developmental Disabilities, 52(2), 98-111.

Janus, A. L. (2009). Disability and the transition to adulthood. Social Forces, 88(1), 99-120. doi://doi.org/10.1353/ sof.0.0248

Jokinen, N. S., Janicki, M. P., Hogan, M., \& Force, L. T. (2012). The middle years and beyond: Transitions and families of adults with Down syndrome. Journal on Developmental Disabilities, 18(2), 59-69. Retrieved from http://oadd.org/journal/volume-18-number-2-special-jointissue-ijds-volume-1-number-1/

Kielland, C. B. (2010). Deinstitutionalisation in Norway: The process, challenges and solutions. Tizard Learning Disability Review, 15(4), 15-21.

Leiter, V., \& Waugh, A. (2009). Moving out: Residential independence among young adults with disabilities and the role of families. Marriage \& Family Review, 45(5) 519-537. doi://doi.org/10.1080/01494920903050847

Marston, G., \& McDonald, C. (2006). Analysing social policy: A governmental approach. Cheltenham, UK: Edward Elgar Publishing.

Ministry of Social Development. (2015). NZ disability strategy. Office for Disability Issues. Wellington, NZ. Retrieved from http://www.odi.govt.nz/nzds/

New Zealand Parliamentary Counsel Office. (1975). Disabled Persons Community Welfare Act 1975 No 122 (as at 3 March 2010), Public Act Contents - New Zealand Legislation. Retrieved from http://www.legislation.govt. nz/act/public/1975/0122/latest/DLM436790.html

New Zealand Parliamentary Counsel Office. (1989). Children, Young Persons, and Their Families Act 1989 No 24 (as at 6 December 2014), Public Act Contents - New Zealand Legislation. Retrieved from http://www.legislation.govt.nz/act/public/1989/0024/ latest/DLM147088.html\#DLM150001

New Zealand Parliamentary Counsel Office. (2000). New Zealand Public Health and Disability Act 2000 No 91 (as at 30 June 2015), Public Act Contents New Zealand Legislation. Retrieved from http://www.legislation.govt.nz/act/public/2000/0091/ latest/DLM80051.html

New Zealand Parliamentary Counsel Office. (2001). Health and Disability Services (Safety) Act 2001 No 93 (as at 5 August 2013), Public Act Contents - New Zealand Legislation. Retrieved from http://www.legislation.govt. nz/act/public/2001/0093/latest/DLM119975.html

New Zealand Parliamentary Counsel Office. (2014). Vulnerable Children Act 2014 No 40 (as at 01 July 2015), Public Act 5 Interpretation - New Zealand Legislation. Retrieved from http://www.legislation.govt. nz/act/public/2014/0040/latest/DLM5501627.html

Nirje, B. (1969). The normalization principle and its human management implications. In R. Kugel \& W. Wolfensberger (Eds.), Changing residential patterns for the mentally retarded (pp. 363-376). Washington, DC: President's Committee on Mental Retardation.

Nirje, B. (1985). The basis and logic of the normalization principle. Australia and New Zealand Journal of Developmental Disabilities, 11(2), 65-68. doi://doi. org/10.3109/13668258509008747

Oliver, M. (1990). The politics of disablement: A sociological approach. In Oliver, M. (Ed) The politics of disablement: A sociological approach (pp. 7-8). London, UK: Palgrave Macmillan.

Oliver, M. (2013). The social model of disability: Thirty years on. Disability \& Society, 28(7), 1024-1026. doi://doi.org/1 $0.1080 / 09687599.2013 .818773$

Owens, J. (2015). Exploring the critiques of the social model of disability: The transformative possibility of Arendt's notion of power. Sociology of Health \& IIIness, 37(3), 385-403. http://doi.org/10.1111/1467-9566.12199

Pallisera, M., Vilà, M., \& Fullana, J. (2014). Transition to adulthood for young people with intellectual disability: Exploring transition partnerships from the point of view of professionals in school and postschool services. Journal of Intellectual and Developmental Disability, 39(4), 333-341. http://doi.org/10.3109/13668250.2014.938032

Palmer, S. B. (2010). Self-determination: A life-span perspective. Focus on Exceptional Children, 42(6), 1-16. 
Schlossberg, N. K. (1995). The transition framework. In M. Anderson, J. Goodman, \& N. K. Schlossberg (Eds.), Counseling adults in transition: Linking practice with theory (p. 28). Springer Publishing. Retrieved from https://books.google.co.nz/books?id=BCobGX6ofOMC

Shakespeare, T. (1999). "Losing the plot"? Medical and activist discourses of contemporary genetics and disability. Sociology of Health \& IIIness, 21(5), 669-688. doi://doi.org/10.1111/1467-9566.00178

Shakespeare, T. (2013). Facing up to disability. Community Eye Health Journal, 26(81), 1-3.

Shakespeare, T., \& Watson, N. (2001). The social model of disability: An outdated ideology? In S. Barnett \& B. Altman (Eds.), Exploring theories and expanding methodologies: Where we are and where we need to go (Vol. 2, pp. 9-28). Emerald Group. Retrieved from http://www.emeraldinsight. com/doi/abs/10.1016/S1479-3547(01)80018-X

Stewart, C., Gates, S., Milner, P., Mirfin-Veitch, B., \& Schumayer, D. (2008). An examination of the outcome of the resettlement of residents from the Kimberley Centre. The Donald Beasley Institute. Retrieved from http://www.health.govt.nz/publication/examinationoutcome-resettlement-residents-kimberley-centre

Vehmas, S., \& Shakespeare, T. (2014). Disability, harm, and the origins of limited opportunities. Cambridge Quarterly of Healthcare Ethics, 23(1), 41-7.

Weinbach, H. (2009). Commentary on "deinstitutionalisation and community living for people with intellectual disabilities in Austria". Tizard Learning Disability Review, 14(1),14-17)

Werner, S. (2015). Public stigma and the perception of rights: Differences between intellectual and physical disabilities. Research in Developmental Disabilities, 38, 262-271. doi://doi.org/10.1016/j.ridd.2014.12.030

World Health Organisation. (2015). WHO Disabilities. Retrieved from http://www.who.int/topics/disabilities/en |

Winn, S., \& Hay, I. (2009). Transition from school for youths with a disability: Issues and challenges. Disability \& Society, 24(1), 103-115. doi://doi. org/10.1080/09687590802535725

Wolfensberger, W. (1977). The normalization principle and some major implications to architectural-environmental design. In M.J Bednar (Ed). Barrier free environments. (2nd, pp.135-166) Stroudsburg: Dowden, Hutchinson \& Ross.

Wolfensberger, W. (1983). Social role valorization: A proposed new term for the principle of normalization. Mental Retardation, 21(6), 234-239. 